\title{
Discussion and Research of Photovoltaic MPPT Methods
}

\author{
Guangya Liu and Mingxiu Cheng*
}

College of Electrical and Electronic Engineering, Hubei University of Technology, Wuhan, 430068, Hubei Province, China

\begin{abstract}
Photovoltaic power generation is one of the ways using solar energy resources effectively. In recent years, it has received the world's attention and has been under rapid development. At present, one of the main problems faced by the photovoltaic power generation is the low conversion efficiency. One way to solve this problem is carrying out the maximum power point tracking in the photovoltaic power generation process. The paper focuses on the implementation of the Conductance Increment Method, and carries on the simulation results. Created the photovoltaic cells simulation model and the photovoltaic maximum power point tracking model in MATLAB, the simulation and analysis are carried out.
\end{abstract}

Keywords: The maximum power point tracking, photovoltaic battery, the conductance increment, the fuzzy logic control.

\section{INTRODUCTION}

Solar energy is a kind of mine and unlimited energy. At present, energy crisis is quite alarming throughout the world, in order to get the sustainable development of human beings, the wide application of solar energy has become undoubtedly the trend of the times. Solar energy photovoltaic power generation technology is one of the most important fields in the use of solar energy. Photovoltaic battery is the key component in the course of solar energy transforming into electricity. It is made using the semiconductor's photovoltaic effect, which is a conversion device which can change the solar energy into electric energy directly.

There are some inherent defects of solar energy, such as uneven distribution, light intensity change and so on. Photovoltaic battery's characteristic is nonlinear and vulnerable to environmental factors, so in order to improve the utilization rate of solar energy, how to improve the photoelectric conversion efficiency is an important part in the research of solar photovoltaic power generation.

\section{PHOTOVOLTAIC BATTERY}

The working principle of photovoltaic battery is that when light irradiates photovoltaic cell surface, parts of the photons are absorbed by silicon material. At the same time, the photon energy transfers to the silicon atom, makes the electronic move, and the electronic becomes a free electron. Many electronics on both sides of the p-n junction cluster and form potential difference. When external circuit processes, because of this voltage, a current through the external circuit passes producing a certain output [1]. The essence of this process is that photon energy changes into electrical energy.

*Address correspondence to this author at the College of Electrical and Electronic Engineering, Hubei University of Technology, Wuhan, 430068, Hubei Province, China;

E-mails:whltxz@yahoo.com.cn;whltxz@aliyun.com
Before the analysis of the characteristics of the photovoltaic battery, photovoltaic battery should be equivalent to the basic circuit form, which is shown in figure one. Fig. (1a) shows the equivalent circuit of photovoltaic battery in ideal form while Fig. (1b) in physical form.

According to the definition of each variable in circuits, variable equations can be listed and they are as follows:

$$
\begin{aligned}
& I_{D}=I_{0}\left(\exp \frac{q U_{D}}{A k T}-1\right) \\
& I_{L}=I_{p h}-I_{D}-\frac{U_{D}}{R_{s h}}=I_{p h}-I_{0}\left[\exp \left(\frac{q\left(U_{\infty}+I_{L} R_{s}\right)}{A k T}\right)-1\right]-\frac{U_{D}}{R_{s h}} \\
& I_{s c}=I_{0}\left(\exp \frac{q U_{\infty}}{A k T}-1\right) \\
& U_{\infty}=\frac{A k T}{q} \ln \left(\frac{I_{s c}}{I_{0}}+1\right)
\end{aligned}
$$

and

$\mathrm{I}_{\mathrm{ph}}$ light-generated current;

$\mathrm{I}_{\mathrm{D}}$ dark current;

$\mathrm{I}_{\mathrm{L}}$ cell output current;

$\mathrm{U}_{\text {oc }}$ cell open-circuit voltage;

$\mathrm{R}_{\mathrm{L}}$ cell outside load resistance;

$\mathrm{R}_{\mathrm{S}}$ series resistance.;

$\mathrm{R}_{\mathrm{sh}}$ shunt resistance;

$I_{O} p-n$ junction reverse saturation current of the internal equivalent diode in photovoltaic cell;

$\mathrm{I}_{\mathrm{sc}}$ cell short-circuit current;

$\mathrm{U}_{\mathrm{D}}$ across voltage of equivalent diode;

q electronic charge, $1.6 \times 10-19 C$; 


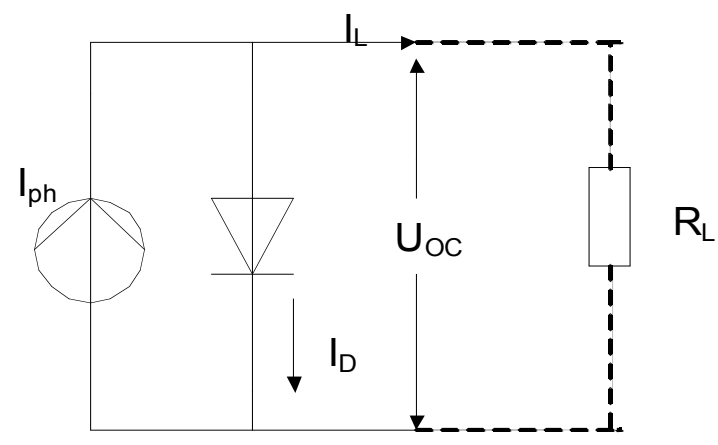

(a)

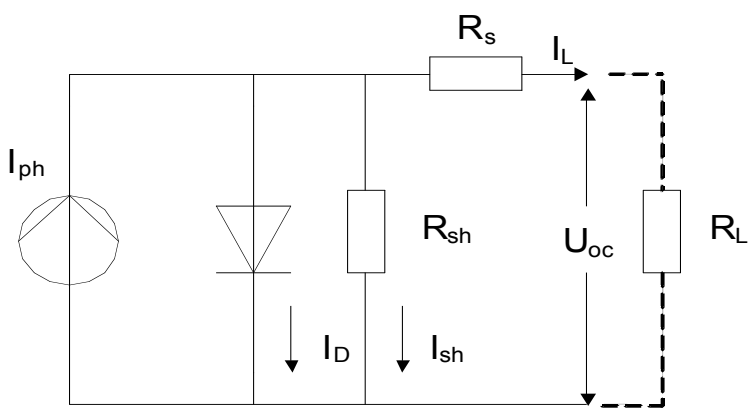

(b)

Fig. (1). equivalent circuit of the photovoltaic battery.

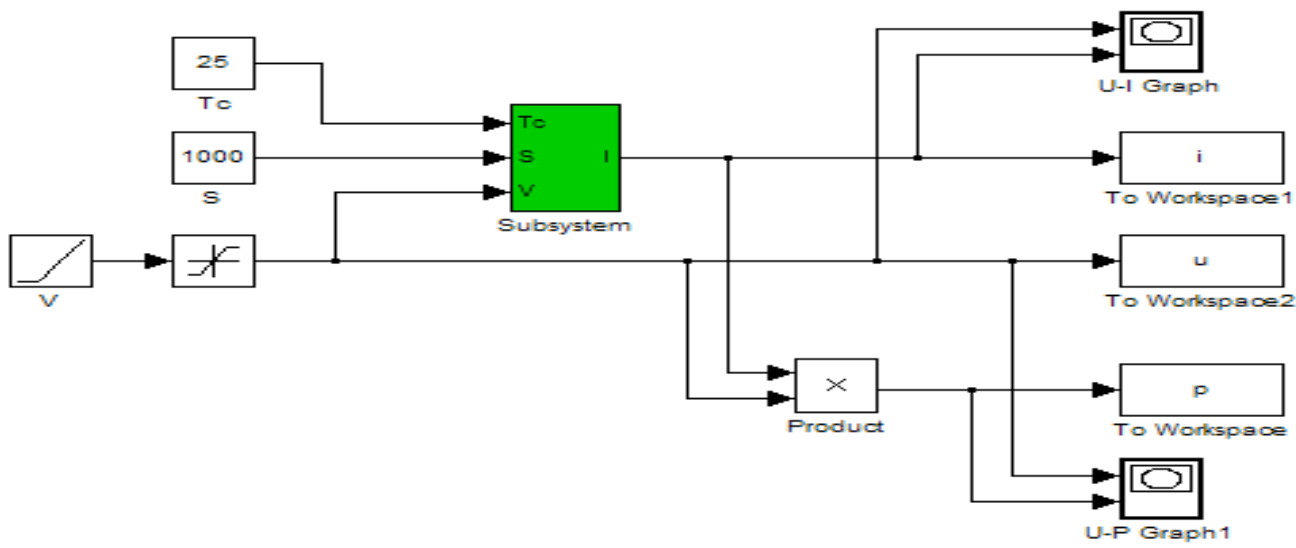

Fig. (2). photovoltaic cell array simulation model.

k Boltzmann's constant, $0.86 \times 10-4 \mathrm{eV} / \mathrm{K}$;

$\mathrm{T}$ absolute temperature;

A constant of the $p-n$ junction curve

In the condition of weak light, because of $\mathrm{Iph} \leq \mathrm{IO}$, it makes

$U_{o c}=\frac{A k T}{q} \cdot \frac{I_{p h}}{I_{O}}$

In the condition of strong light, because of $\mathrm{Iph} \geq \mathrm{IO}$, it makes

$U_{o}=\frac{A k T}{q} \ln \frac{I_{p h}}{I_{O}}$
From the analysis above, it is known that under the weak light the curve of the Uoc and light intensity approximates a linear. While under the strong light, the curve of the Uoc and light intensity approximates a logarithmic relationship. In general, silicon photovoltaic cell's open circuit voltage is between $0.5 \mathrm{~V}$ and $0.58 \mathrm{~V}$.

The equation for the equivalent circuit in the ideal form $\left(\mathrm{R}_{\mathrm{S}} 0 \mathrm{R}_{\mathrm{sh}} \infty\right)$ is:

$I_{L}=I_{p h}-I_{D}-\frac{U_{D}}{R_{s h}} \approx I_{p h}-I_{D}$

Photovoltaic battery general Simulink simulation model which is shown in Fig. (3) is deduced from the photovoltaic battery output characteristic and this model is integrated as the 


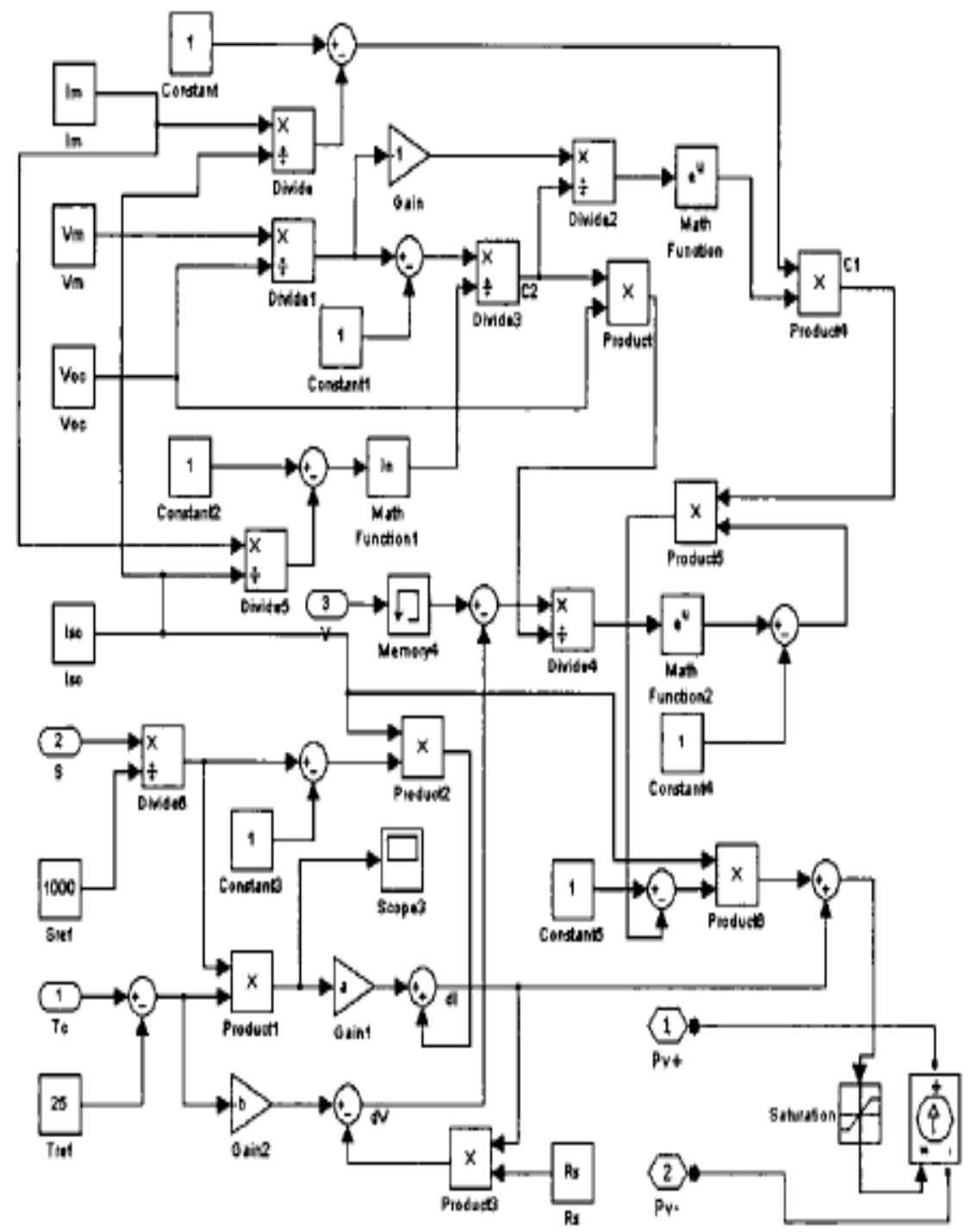

Fig. (3). Photovoltaic battery general Simulink simulation model.

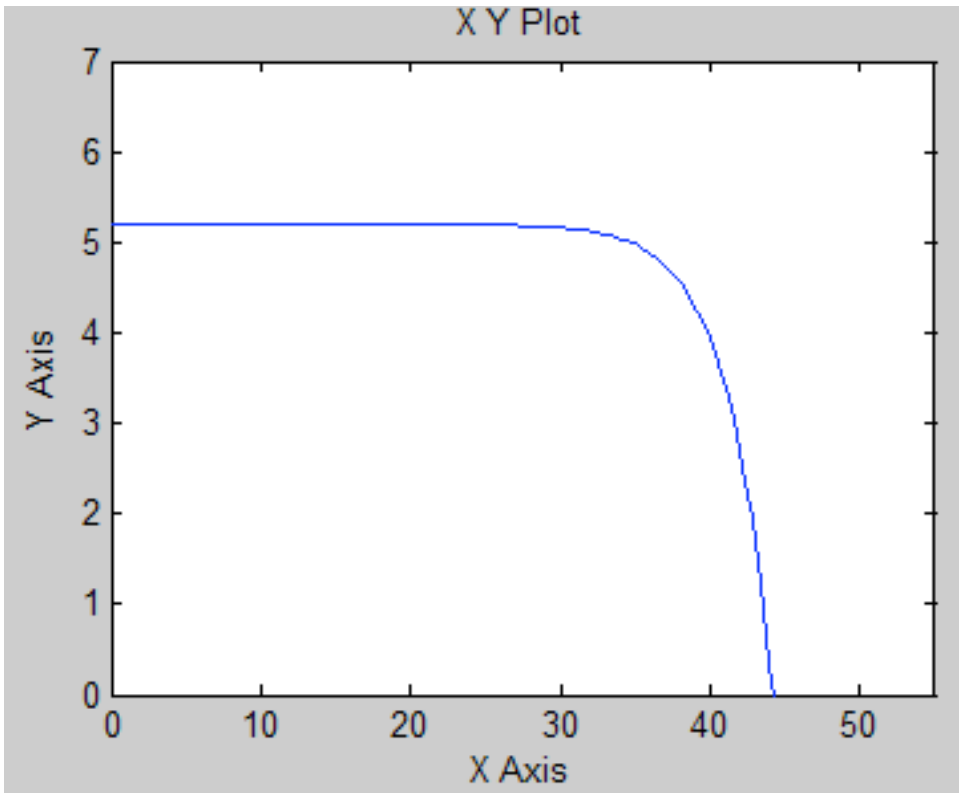

(a) 
Fig. (4). Contd...

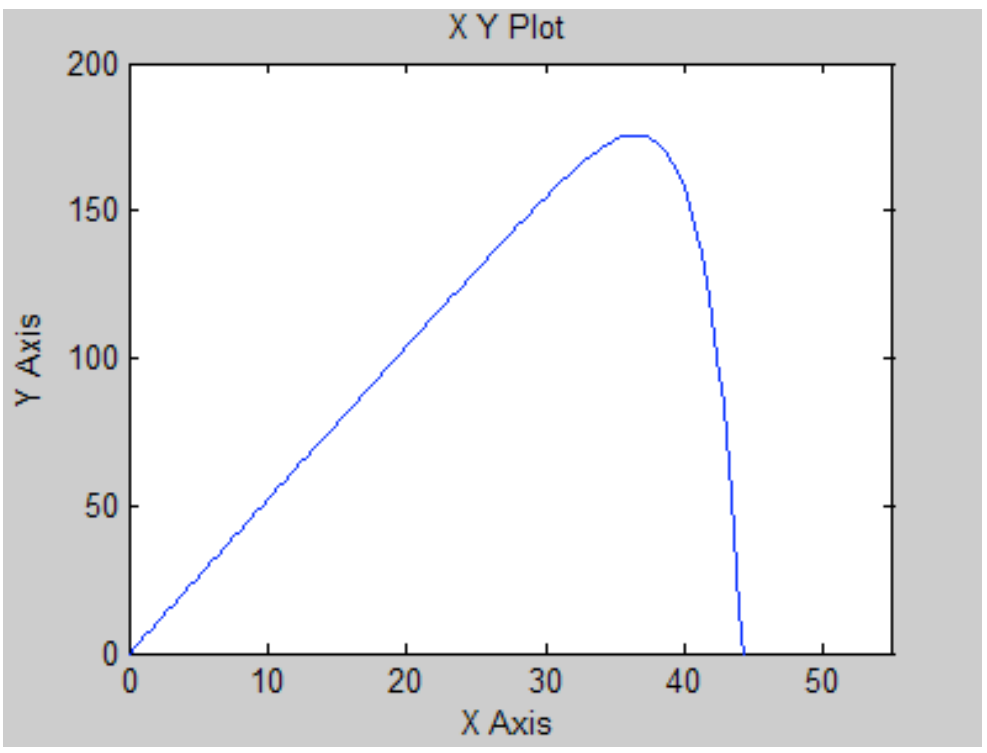

(b)

Fig. (4). the simulation results. (a) output U-I simulation curve; (b) output U-P simulation curve

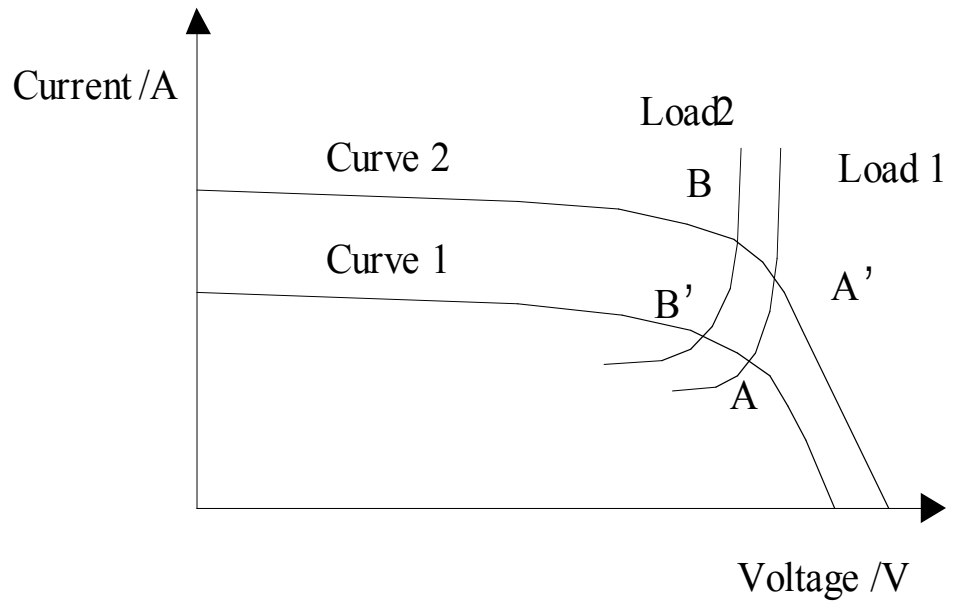

Fig. (5). MPPT algorithm analysis diagram.

subsystem in Fig. (2). Photovoltaic cell array simulation model is shown in Fig. (2). In this figure, the device named Subsystem is the photovoltaic battery integrated packaging. Its output U-I curve simulation is shown in Fig. (4a), and output U-P simulation curve is shown in Fig. (4b).

\section{INTRODUCTION OF THE MPPT'S PRINCIPLE AND METHODS}

Photovoltaic array's output is affected by light intensity, environmental temperature and the load condition. Ensuring that light intensity and environment temperature are changeless, photovoltaic battery can work at different working voltage by changing the size of the load. But only at a certain voltage value, photovoltaic cell can get the maximum output power. This point is called the maximum power point (MPP) which is the highest point in the photovoltaic battery output voltage curve. So by adjusting the photovoltaic battery's working point, the system will work near the maximum power point, this process is called the maximum power point tracking (MPPT).

As is shown in Fig. (5), curve 1 and curve 2 are the photovoltaic battery's output characteristic curves in different light intensity. A \& B are the maximum power points respectively for each of these curves. If the system works on A point, PV curve rises from curve 1 to curve 2 with the change of light intensity. In this case, the system should run on point $A^{\prime}$ when the load is constant. But the load should change to load 2 in order to track the maximum power point continually. This method ensures that the system can run near maximum power point every time, this is also the basic principle of the MPPT algorithm [2].

There are several kinds of methods about MPPT control. Constant Voltage Tracking, Perturb \& Observe Algorithms and Actual Measurement are the methods commonly used. 


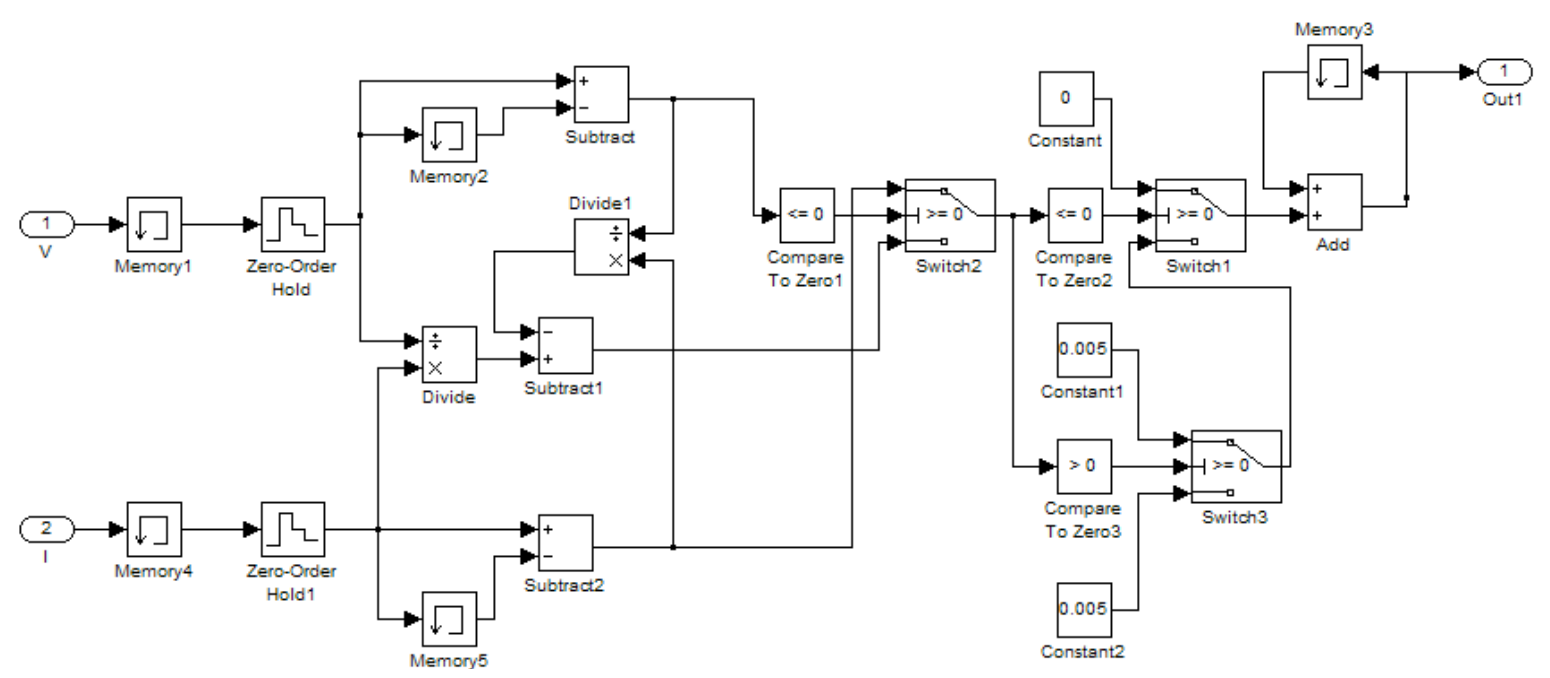

Fig. (6). the MPPT based on ICA's Smulink simulation module.

Constant Voltage Tracking (CVT) is the simplification and approximation for MPPT. In different light intensity, the photovoltaic array's MPP is different. CVT is to measure the voltage $(\mathrm{Um})$ in different illumination and temperature. Then the system adjusts voltage output cording to the light and temperature at that time. That can make the system run close to the MPP and give the maximum power. CVT control method is simple, convenient and feasible, but not for the environment changing sharply.

The actual measurement method needs to choose a piece of photovoltaic battery as reference object firstly. And its MPP should be obtained by survey and analysis. Then this MPP is taken as the reference to control other photovoltaic batteries. This control method is accurate. But reference cells cost too much for large-scale photovoltaic systems. It cannot be guaranteed that all photovoltaic batteries' working environment is consistent with reference objects', too [3].

Perturb \& Observe Algorithms ( $\mathrm{P} \& \mathrm{O}$ ) should make sure the disturbance $(\Delta \mathrm{V})$ direction firstly. It is achieved by comparing powers of the present moment and the previous moment. If the power is larger at this moment, it proves the disturbance in the right direction, and the output voltage should move in the same direction $(+\Delta \mathrm{V})$. While if the power becomes smaller, the disturbance direction should be on the contrary, and output voltage is reverse to the perturbation direction $(-\Delta \mathrm{V})$. This method can get the real-time MPP of the system and it can be implemented simply. But because there always exists $\pm \Delta \mathrm{V}$, it will result in some loss of power in MPPT process. If the search step $\Delta \mathrm{V}$ is too small, the search speed will be too slow. On the other hand, it is easy to cause oscillation. And when the outside world's environmental conditions change, it cannot track quickly [4].

Incremental Conductance Algorithm (ICA) is a new method which is based on P\&O. When the system gets the maximum power (Pmax), equations will be achieved as follows.

$$
\begin{aligned}
& \frac{d P}{d U}=\frac{d(U I)}{d U}=I+U \frac{d I}{d U}=0 \\
& \frac{d I}{d U}=-\frac{I}{U}
\end{aligned}
$$

The system will run at MPP, if the values of the voltage (U) and current (I) suit for both of the equations above. In other words, when the conductance and the variation of the conductance are equal to the opposite number, photovoltaic cell works at MPP. This method needs to sample the values of photovoltaic system's conductance and conductance increment, and the comparison of the two values to change the control signal. The overall design scheme needs to set a voltage reference value at first. In order to calculate the instantaneous power, it needs to get the photovoltaic system's output voltage and current by real-time detection. At last, it needs to compare the instantaneous power with the reference power. If instantaneous power is less than the reference value, the direction of the disturbance needs to be changed and then the reference voltage value is obtained. But if more than or equal to the reference power, disturbing direction is kept same and this voltage value is obtained. The control of ICA is precision and its respond speed is very fast. It is suitable for the occasion where changes occur fast. But, it requires a precision sensor. This control algorithm has some outstanding advantages. For example, when the illumination changes, tracking mode is smooth and concussion in steady state is small. The MPPT based on ICA's Smulink simulation module is shown in Fig. (6). Its input waveform is shown in Fig. (7a) and the output waveform is shown in Fig. (7b).

The control flow chart bases on ICA are shown in figure 8. The photovoltaic array's voltage and current values are represented as Un or In in Fig. (8). Ub and Ib are sampling values in last sampling period. The biggest advantage of the MPPT control algorithm is that when the light intensity is changing, PV array output voltage can track the change smoothly, and steady state of the shock is smaller than the Perturb \& Observe Algorithms.

Many factors need to be considered due to the uncertainty of the solar light intensity, PV array temperature changes, load changes and the PV array output characteristics of the non-linear characteristics, to achieve accurate tracking of the maximum power point of the PV array. For nonlinear systems, the use of fuzzy logic control methods for controlling can get ideal results. 


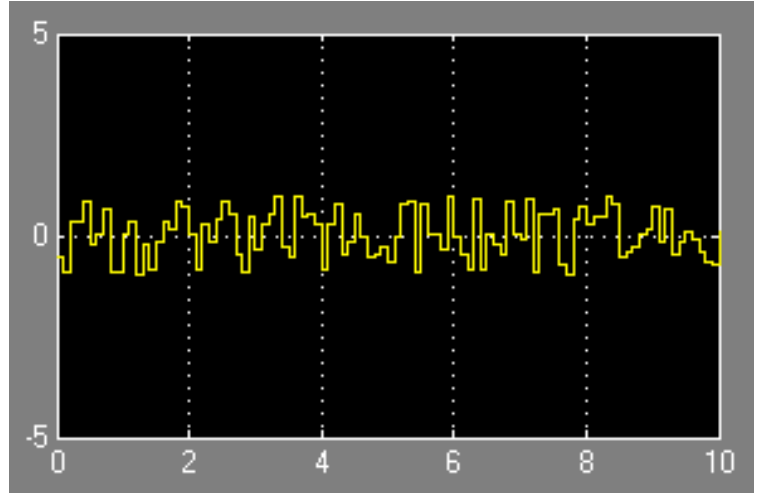

(a)

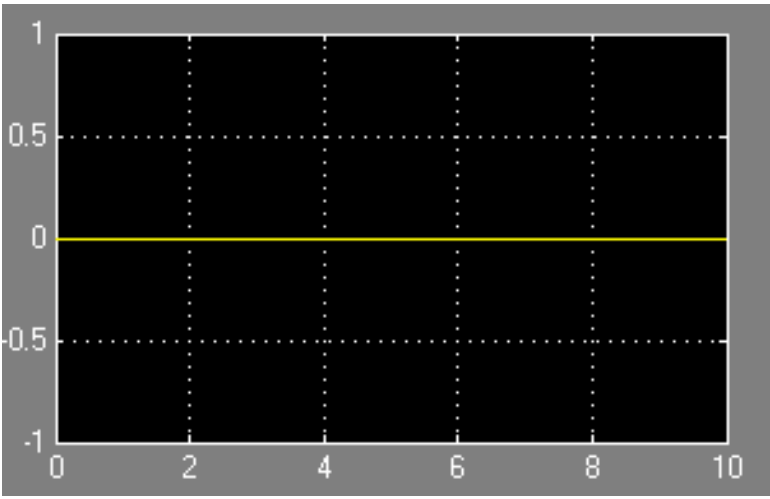

(b)

Fig. (7). Simulation's input and output waveforms.

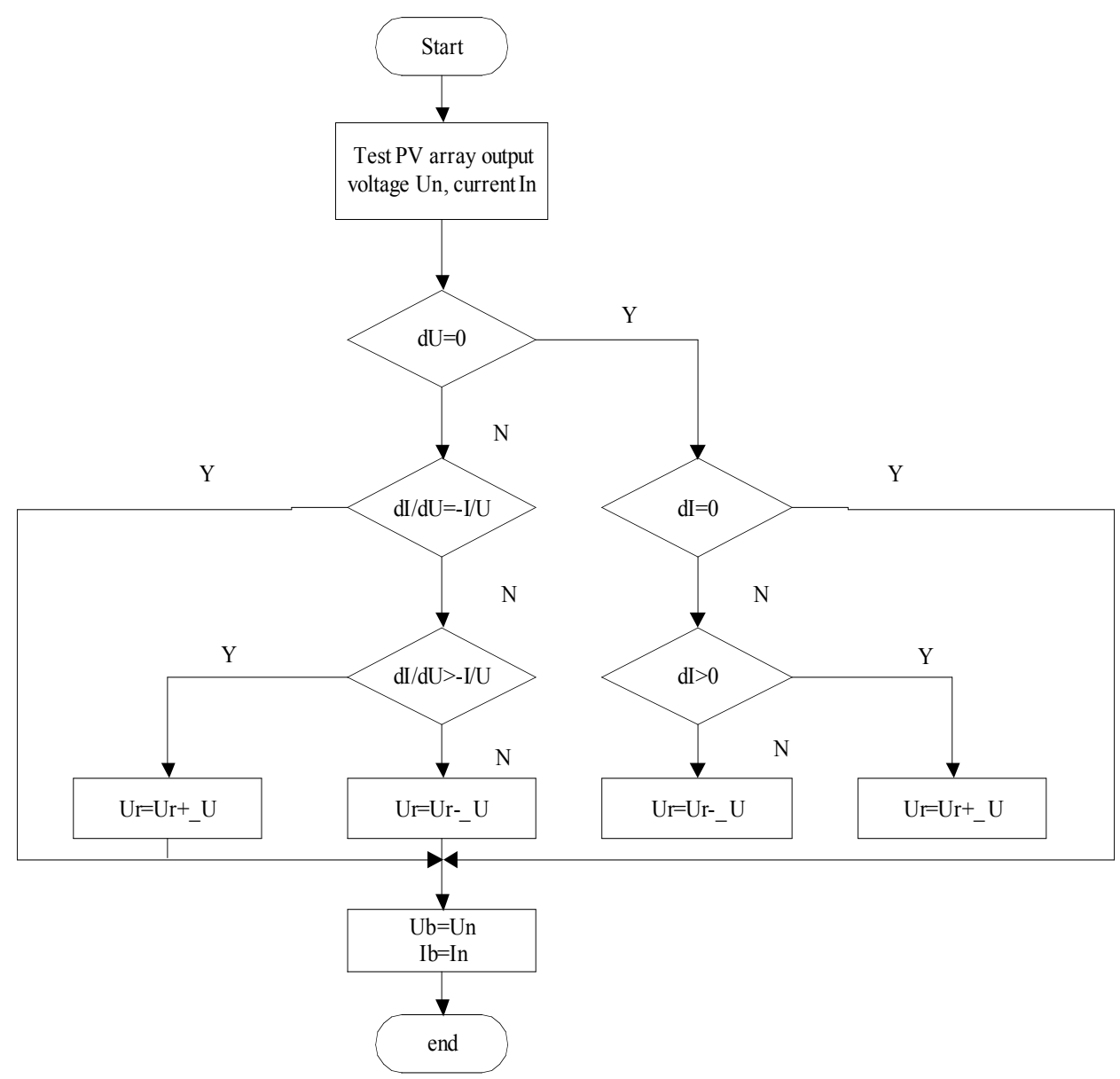

Fig. (8). the control flow chart bases on ICA.

Using fuzzy logic control method in MPPT, control of photovoltaic power generation system can be easily executed by the DSP, controller design includes the following aspects, we must first determine the input and output variables of the fuzzy controller; Secondly, we should summarize the control of fuzzy control rules; then determine fuzzification and defuzzification methods; Finally, we should select the domain and determine the relevant parameters.

Fuzzy control logic used in PV system's MPPT control has a good dynamic characteristics and precision, and also has very broad application prospects. Fig. (9) shows a con- trol flowchart for the photovoltaic power generation system using the fuzzy logic control method.

Traditional fuzzy control simulation's output curves of photovoltaic cells are shown in Fig. (10). As it can be seen from the simulation results, the fuzzy control can respond quickly to the changes in the external environment, the PV system always gives the maximum power; fuzzy control characteristics being unique to find excellent system can only control the operating point to swing back and forth near the maximum power point what is called oscillation phenomenon. The classic PID control can effectively eliminate 


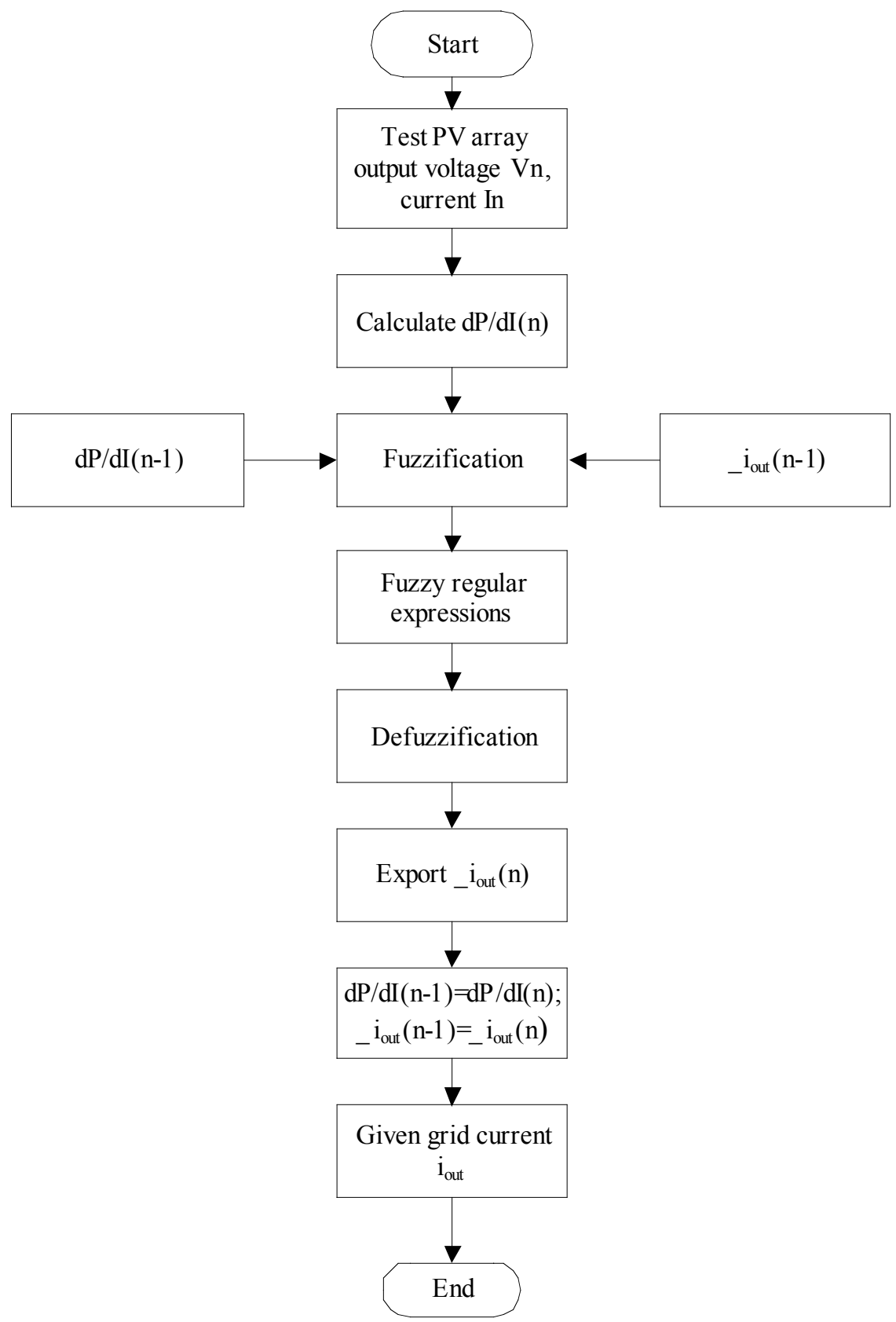

Fig. (9). The flow chart for the photovoltaic power generation system using fuzzy logic control method.

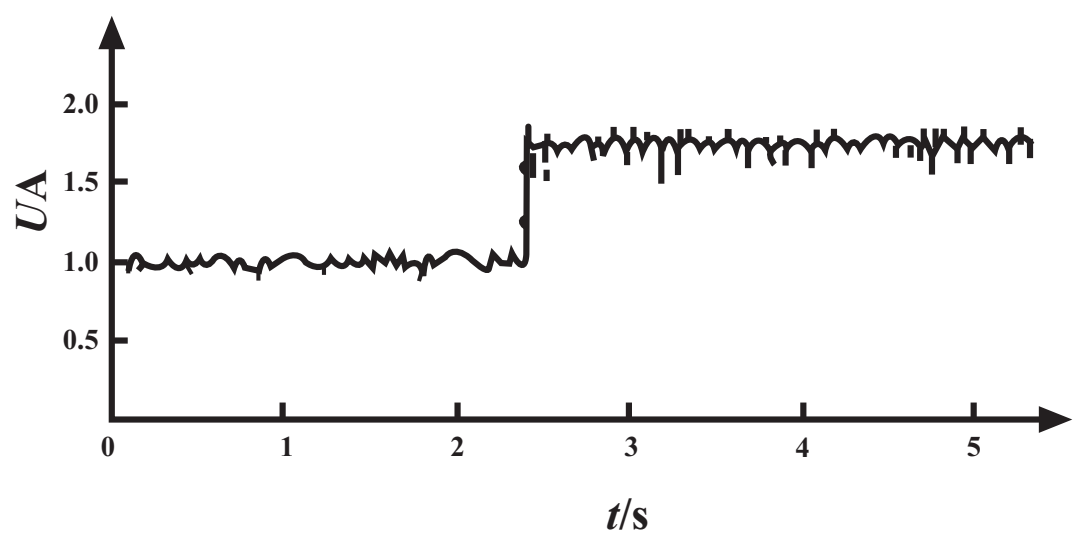

(a) 


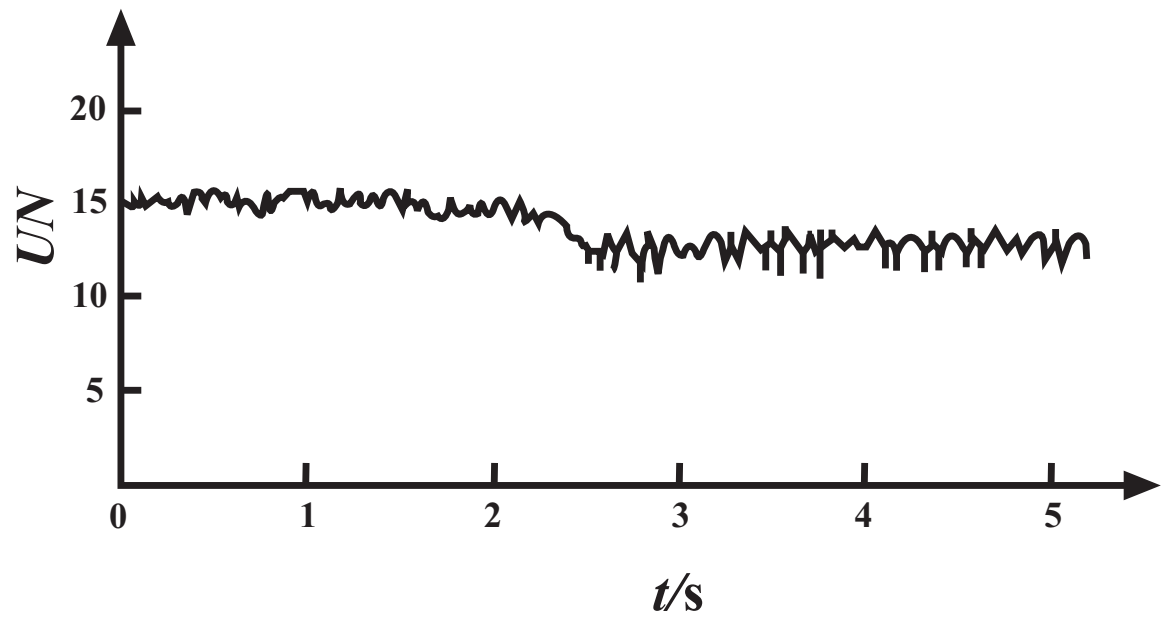

Fig. (10). Contd..

(b)

Fig. (10). Traditional fuzzy control simulation's output curves of photovoltaic cells. (a) output I-t simulation curve; (b) output U-t simulation curve.

the oscillation of the work at the point and is easy to be implemented; practical applications can be considered a combination of both methods.

\section{CONCLUSIONS}

Solar photovoltaic power generation technology has great development potential. How to improve the photovoltaic battery's output power should be considered firstly in the process of this technology's application, MPPT control algorithm is now commonly used as a solution. The algorithm itself is not perfect and control system's precision should be improved, so the MPPT control algorithm still has wide research space. Intelligent control algorithm is introduced to the MPPT control algorithm that makes MPPT further optimized. Light intensity causes uncertainty and the changes of temperature, load conditions and PV array's output characteristics of the photovoltaic array are nonlinear. Those characteristics phase with the fuzzy control method of the intelligent control can obtain good effect. This is an important development direction in the use of the MPPT control algorithm.

\section{CONFLICT OF INTEREST}

The authors confirm that this article content has no conflicts of interest.

\section{ACKNOWLEDGEMENTS}

Declared none.

\section{REFERENCES}

[1] L. Jie, "Photovoltaic MPPT control system", Publishing House of Zhejiang university, Hangzhou, 2011 (in Chinese).

[2] Z. Zhengming, L. Jianzheng, "Solar photovoltaic power generation and its application". Publishing House of Science Press, Beijing, 2005.(in Chinese).

[3] H. Bolin, "Based on AVR MCU's solar photovoltaic electric control system". Publishing House of Jilin University, Changchun. 2011 (in Chinese).

[4] W. Yan. "Photovoltaic power generation system of MPPT control method". Publishing House of North China Electric Power University, Beijing. 2007 (in Chinese).

Received: July 02, 2013

Revised: July 13, 2013

Accepted: July 14, 2013

(C) Liu and Cheng; Licensee Bentham Open.

This is an open access article licensed under the terms of the Creative Commons Attribution Non-Commercial License (http://creativecommons.org/licenses/by-nc/3.0/) which permits unrestricted, non-commercial use, distribution and reproduction in any medium, provided the work is properly cited. 